\title{
Headache in Smartphone Users: A Cross-Sectional Study
}

\begin{abstract}
Keywords: Headache; Smartphone; Addiction
Abstract

Objective: Usage of smartphones has increased rapidly and it may result in smartphone addiction. The aim of this study was to investigate the frequency of headache in smartphone users and to compare the headache characteristics between smartphone users and controls in university students.
\end{abstract}

Methods: 242 (159 (65.7\%) females, 83 (34.3\%) males) university students were included in this study. Participants were divided into three groups; Smartphone non-users $(n=50)$, low smartphone users $(n=96)$ and high smartphone users $(n=96)$. Informations about smartphone using and headache features were recorded for all participants. Subjects except smartphone non-user group were also assessed with the Smartphone Addiction Scale.

Results: The findings revealed that the headache complaints were significantly higher in the high smartphone users $(51 \%)$ than the low smartphone users $(34.4 \%)(p=0.02)$. Duration and frequency of headache attack were higher in the high smartphone users $(7.95 \pm 5.29$ and $8.73 \pm 4.31$, respectively) than the low smartphone users (4.96 \pm 3.36 and $6.15 \pm 3.29$, respectively) and smartphone non-users (3.50 \pm 2.87 and $3.87 \pm 1.82$, respectively) ( $p<0.05$ for all). There were significantly positive correlations between the Smartphone Addiction Scale scores and duration and frequency of headache attack ( $r=0.549, p<0.001$, $r=0.523, p<0.001$, respectively). Moreover, using analgesics to relieve headache was higher in smartphone users than smartphone non-users $(p<0.001)$.

Conclusion: The results of the present study suggest that headache may be associated with smartphone use. Therefore, smartphone overusers should be considered for carefully monitoring for headache.

\section{Introduction}

Smartphones are popular technological devices, capable of processing more information than other mobile phones and having many properties including internet access, multimedia and navigation in addition to use for communication [1]. The number of estimated smartphone users in the world was more than 1.08 billion in early 2012, and the use of smartphones has increased rapidly [2].

The use of smartphones might result in smartphone addiction which is similar to many aspects of internet and cell phone addiction [3]. But, there are also some differences such as the easy portability, real-time internet access and easy and direct communication features of smartphones [4]. Behavior addictions, such as smartphone addiction, are usually difficult to define due to the fact that they are related both to physical and social and psychological aspects [5]. There is no official diagnostic criterion for smartphone addiction. Smartphone addiction has been defined as the overuse of smartphones to the extent that it disturbs the users' daily lives. It has been reported that the rate of smartphone addiction is $8.4 \%$ [6].

Excessive smartphone use can cause physical health-related problems such as blurred vision and pain in the wrists or neck [7]. Excessive smartphone use may also lead to some mental or

\section{Journal of}

Neurology and Psychology

\section{Seden Demirci ${ }^{1 *}$, Kadir Demirci ${ }^{2}$ and Mehmet Akgonul ${ }^{2}$}

${ }^{I}$ Department of Neurology, Süleyman Demirel University, Faculty of Medicine, Isparta, Turkey

${ }^{2}$ Department of Psychiatry, Süleyman Demirel University, Faculty of Medicine, Isparta, Turkey

\section{*Address for Correspondence}

Seden Demirci, MD, Department of Neurology, Süleyman Demirel University, School of Medicine, Isparta, Turkey, Tel: +02462119276; Fax: +902462112830; E-mail: sdndemirci@yahoo.com.tr

Submission: 15 February, 2016

Accepted: 02 March, 2016

Published: 07 March, 2016

Copyright: () 2016 Demirci S, et al. This is an open access article distributed under the Creative Commons Attribution License, which permits unrestricted use, distribution, and reproduction in any medium, provided the original work is properly cited.

Reviewed \& Approved by: Dr. Matthew S Robbins, Neurology and Inpatient Headache Services, Einstein Division, Montefiore Medical Center, USA

behavioral problems [8]. Moreover, increasing smartphone use can cause various musculoskeletal problems [9]. Kim et al. reported that long and continuous smartphone use causes posture change in the cervical and lumbar vertebrae, in addition to proprioception deficits in the cervical vertebra [10]. However, to the best of our knowledge, no study has yet investigated association between headache and smartphone addiction. The aim of this study was to investigate the frequency of headache in smartphone users and to compare the headache characteristics between smartphone users and controls in university students.

\section{Materials and Methods}

\section{Participants}

The students of our university were the target population of this study. Three hundred university students randomly selected were considered candidates for this study. The subjects had no history of any disease. Thirty-four of the students refused to participate in this study. Twenty-four students were excluded as their scales were incomplete. The final sample was composed of 242 students (159 females and 83 males; mean age $=21.0 \pm 2.30$ ).

\section{Procedure}

All participants were asked to fill out their information on gender, age, duration of smartphone use, the number of smartphones used before, the most purpose of smartphone use and the average number of hours spent on smartphone per day. Information about the presence of headache, frequency of headache attacks, duration of headache attacks, severity of attacks, unilateral or bilateral localization, associated symptoms, and using analgesics to relieve headache were recorded for all participants. Severity of headache was evaluated to be least severe 1 to most severe 10 according to visual analogue scale (VAS). All participants underwent a thorough physical 
and neurological examination by the same neurologist. The diagnoses of tension type headache and migraine were made according to the International Classification of Headache Disorders-II criteria [11].

All participants except smartphone non-user group were assessed with the Smartphone Addiction Scale (SAS). After they had filled in the questionnaire, the smartphone users were divided into two groups according to the median value of SAS score. Finally, all subjects were divided into three groups; Smartphone non-users, low smartphone users (scores below the median SAS score), high smartphone users (scores over the median SAS score).

\section{Measures}

The SAS is a 33-item, six-point Likert-type self-rating scale developed by Kwon et al. based on internet addiction scale and the characteristics of smartphones. The Cronbach's alpha of the SAS was 0.967 , and the explained variance was 66.4 percent. The options on this scale range from 6 (definitely not) to 1 (absolutely yes). Higher scores show increased risks of smartphone addiction. The total score in the scale can range from 33 to 198. A cut-off point was not reported in the original scale [7]. In a reliability and validity study of the Turkish version of the SAS, the Cronbach's alpha was 0.947 in 301 university students [1]. In this study, Demirci et al.'s original 33-item Turkish version of SAS was used as it was validated on young population.

\section{Statistical analysis}

All statistical analyses were performed using the SPSS 15.0 for Windows. Descriptive statistics were performed to report the analysis of data that was presented as mean \pm standard deviation. The normality of the distribution for all variables was assessed using Kolmogorov-Smirnov test. Categorical variables were shown as frequency and percentages. The independent t-test was used to compare the parametric variables between the groups. Categorical variables were compared between the groups using the chi-square test. Pearson correlation was used to determine the strength of the relationship between the variables. Comparisons of parametric data of the three groups were performed by One-Way ANOVA testing. The post hoc Tukey test was used in case of homogeneity of variance. $P$ values $<0.05$ were regarded as statistically significant.

\section{Ethics}

Informed consent was obtained from all subjects according to the ethical principles of the Declaration of Helsinki. The study was approved by the local ethics committee (Acceptance number: 212). Written informed consent was obtained from all participants.

\section{Results}

Two hundred forty-two students were included in this study. Of all participants, $79.3 \%(\mathrm{n}=192)$ were smartphone users and $20.7 \%(\mathrm{n}=50)$

Table 1: General characteristics of smartphone usage in smartphone users.

\begin{tabular}{|c|c|c|c|}
\hline & & $\mathbf{N}$ & $\%$ \\
\hline \multicolumn{4}{|l|}{ Duration of smartphone use } \\
\hline 1 & 1 years & 85 & 44.3 \\
\hline & 2 years & 35 & 18.2 \\
\hline & 3 years & 28 & 14.6 \\
\hline & 4 years & 21 & 10.9 \\
\hline 4 & 4 years above & 23 & 12 \\
\hline \multicolumn{4}{|l|}{ What number of using smartphones } \\
\hline & First & 127 & 52.5 \\
\hline & Second & 50 & 20.7 \\
\hline & Third & 13 & 5.4 \\
\hline & Fourth & 0 & 0 \\
\hline Fo & Fourth above & 2 & 0.8 \\
\hline \multicolumn{4}{|l|}{ Major using purpose } \\
\hline & Phone call & 42 & 17.4 \\
\hline & Internet access & 83 & 34.3 \\
\hline & Games & 6 & 2.5 \\
\hline & Social networking & 37 & 15.3 \\
\hline & Short text-messaging & 20 & 8.3 \\
\hline & Others & 4 & 1.7 \\
\hline \multicolumn{4}{|l|}{ Daily smartphone use } \\
\hline & $0-4$ hours & 97 & 40.1 \\
\hline & $4-16$ hours & 81 & 33.5 \\
\hline & 16 hours or above & 14 & 5.8 \\
\hline
\end{tabular}


Table 2: General clinical features of the participants.

\begin{tabular}{|l|l|l|l|}
\hline & $\begin{array}{l}\text { Smartphone non-users } \\
\mathbf{n = 5 0}\end{array}$ & $\begin{array}{l}\text { Low smartphone users } \\
\mathbf{n = 9 6}\end{array}$ & $\begin{array}{l}\text { High smartphone users } \\
\mathbf{n = 9 6}\end{array}$ \\
\hline Age (years) & $20.7 \pm 1.99$ & $21.1 \pm 2.67$ & $20.9 \pm 2.05$ \\
\hline Sex, Female, $\mathbf{n}(\%)$ & $26(52)$ & $50(52.1)$ & $83(86.5)$ \\
\hline Headache, $\mathbf{n}(\%)$ & $16(32)$ & $33(34.4)$ & $49(51)$ \\
\hline TTH, $\mathbf{n}$ (\%) & $14(28)$ & $30(31.3)$ & $37(37.5)$ \\
\hline Migraine, $\mathbf{n}(\%)$ & $1(2)$ & $2(2.1)$ & $7(7.3)$ \\
\hline TTH+Migraine, $\mathbf{n}(\%)$ & $1(2)$ & $1(1)$ & $5(5.2)$ \\
\hline Attack duration (hours) & $3.50 \pm 2.87$ & $4.96 \pm 3.36$ & $7.95 \pm 5.29$ \\
\hline Attack frequency (n/month) & $3.87 \pm 1.82$ & $6.15 \pm 3.29$ & 8.02 \\
\hline Headache severity (VAS) & $5.25 \pm 1.80$ & $6.18 \pm 1.55$ & 6.001 \\
\hline Using analgesics to relieve headache, $\mathbf{n}(\%)$ & $7(43.8)$ & $25(75.8)$ & $<.32 \pm 1.74$ \\
\hline
\end{tabular}

VAS: Visual Analogue Scale; TTH: Tension Type Headache; F: Female; M: Male

were not smartphone users. The average SAS score was 76.1 \pm 22.6 in the smartphone users. The SAS scores were statistically significantly higher in females than males in smartphone users (SAS scores were $81.5 \pm 22.9$ and $63.9 \pm 16.5$ respectively, $\mathrm{p}<0.001$ ). The median value of SAS score was found to be 73. According to smartphone use and the median value of SAS score in this study, participants were divided into three different groups; Smartphone non-users, low smartphone users (SAS score $<$ the median value of 73), and high smartphone users (SAS score $\geq$ the median value of 73 ). Of the participants enrolled in the present study, $50(20.7 \%)$ were categorized into the smartphone non-users, 96 (39.7\%) were categorized into the low smartphone users, and 96 (39.7\%) were categorized into the high smartphone users. The three groups were similar in terms of age $(\mathrm{p}=0.32)$. General characteristics of usage smartphone in smartphone users were shown in Table 1. Female:male ratio was significantly higher in high smartphone users than low smartphone users and non-users $(\mathrm{p}<0.001)$.

98 (40.5\%) subjects reported headache complaints in our study sample. Eighty-one of them (82.7\%) were female and the others (17.3\%) were male. According to International Classification of Headache Disorders-II criteria, 81 (82.7\%) of the patients were diagnosed with the tension type headache (TTH), 10 (10.2\%) were with migraine and $7(7.1 \%)$ were with TTH plus migraine. 33 (34.4\%) subjects reported headache complaints in low smartphone users and 49 (51\%) subjects reported headache complaints in high smartphone users. The differences between these groups were statistically significant $(\mathrm{p}=0.02)$. Types of headache were not statistically significant among the groups $(\mathrm{p}=0.45)$. The majority of the smartphone users with headache were using the smartphone for 1 year $(n=37,45.1 \%)$. The most of the smartphone users with headache were using their first smartphone $(n=50,61 \%)$. Major using smartphone purpose was internet access in smartphone users with headache $(n=31,37.8 \%)$. The majority of the smartphone users with headache were also using the smartphone daily $4-16$ hours $(n=43,52.4 \%)$. Duration of smartphone use, the number of smartphones used before and the most purpose of smartphone use categories did not show a significant difference for headache ( $\mathrm{p}=0.97, \mathrm{p}=0.27, \mathrm{p}=0.10$, respectively). The average number of hours spent on smartphone per day categories showed a significant difference for headache $(\mathrm{p}=0.009)$.

Duration of headache attack were higher in the high smartphone users than low smartphone users and smartphone non-users ( $\mathrm{p}=0.009$, $\mathrm{p}=0.002$, respectively). Frequency of headache attack were also higher in the high smartphone users than the low smartphone users and smartphone non-users $(\mathrm{p}=0.007, \mathrm{p}<0.001$, respectively). Also, the frequency of headache was higher in females of high smartphone users than in males of those ( $\mathrm{p}=0.03$ ). Using analgesics to relieve the headache was higher in smartphone users than smartphone nonusers $(\mathrm{p}<0.001)$. Comparisons among low smartphone users, high smartphone users and smartphone non-users in terms of the general clinical features were given in Table 2.

The smartphone use severity was positively correlated with the duration of headache attack $(\mathrm{r}=0.549, \mathrm{p}<0.001)$ and frequency of headache attack $(r=0.523, p<0.001)$. No correlation was found between the smartphone use severity and VAS $(r=0.102, \mathrm{p}=0.362)$.

\section{Discussion}

We found four main results in the present study. Firstly, headache complaints were significantly higher in the high smartphone users than the low smartphone users. Secondly, duration and frequency of headache attack were higher in the high smartphone users than the low smartphone users and smartphone non-users. Thirdly, using analgesics to relieve the headache was higher in smartphone users than smartphone non-users. Finally, there were significantly positive correlations between the SAS scores and duration and frequency of headache attack. According to the best of our knowledge, this is the first study that shows the relationship between the severity of smartphone usage and headache in the university students.

The use of smartphones has grown at a rapid rate in modern society. It may result in smartphone addiction. Excessive smartphone use may cause a number of physical and psychological health problems. Kayode et al. reported increased headache, eyestrains, double vision, redness of eye, blurred eye and irritation of eyes in smartphone users as a result of spending much time on smartphone [12]. Lee et al. evaluated the relationship between the hours of smartphone use and neck pain in university students. The researchers found that total time spent daily using smartphones had a strong positive correlation with pain intensity, lifting, reading, headache, concentration, and driving in neck disability index and suggested that long-time use of smartphone had a strong relationship with neck pain [13]. Hwang et al. reported that shoulder pain, state anxiety, trait anxiety, and depression were higher in the smartphone overusers than in the normal users among college students [3]. Lemola et al. found that smartphone ownership was associated with later bedtimes but it was not related to sleep disturbance [14]. A study investigating the cervical repositioning 
errors according to smartphone addiction grade showed that severe addiction group had the largest errors. The researchers suggested that when smartphone addiction becomes more severe, a person is more probable to display impaired proprioception and ability to recognize the right posture [15]. Our results showed that headache complaints were related to severity of smartphone using.

Because smartphone addiction is the convergence of existing mobile phone and internet addiction problems [3], adverse effects of overuse smartphone may be similar with those of problematic mobile phone and internet. Khan investigated the adverse effects of excessive mobile phone usage in medical students and reported that $16.08 \%$ of the participants complained of headache [16]. A study evaluating the type and incidence of subjective symptoms associated with the use of mobile phones in Polish users showed that headaches were reported significantly more frequent by the subjects talking frequently and long compared with other users and also, $26 \%$ of the participants reported continuous headache, persisting for longer than $6 \mathrm{~h}$ since the end of a call [17]. Chu et al. found that headache associated with mobile phone use showed mostly stereotyped clinical features such as mild intensity, a dull or pressing quality, ipsilateral location to the side of mobile phone use, related to a burning sensation, and provocation by prolonged mobile phone usage. The researchers suggested that altering conditions during mobile phone usage including radiofrequency fields, psychological factor, temperature change, noise and various combinations thereof could induce headache during or after mobile phone use [18]. It was reported that usage of mobile phones caused changing in cerebral blood flow and altered electroencephalogram patterns [19].

We found markedly elevated female:male ratio in high smartphone users. Our results were inconsistent with the results of previous studies $[1,20,21]$. This difference might be associated with the usage pattern or purpose, such as increased use of social networks in females. Also, the frequency of headache was higher in this group of women than in men in this group. Plausible reasons for our findings on headache in our study may as follows. Exposure to radiofrequency fields during smartphone use has been suggested to trigger headache [22]. The involvement of the blood brain barrier and the dopamine-opioid systems of the brain in headaches are linked to radiofrequency exposures [23]. Smartphone using may change head posture and neck mobility [13]. It has been demonstrated that patients with chronic TTH has a greater forward head posture and lesser neck mobility [24] and musculoskeletal dysfunction of the neck is a contributing factor to the etiology of migraine and tension headache [25]. Smartphone use is related to later bedtimes [14]. Therefore, sleep dysregulation may trigger episodic TTH, and sleep disorders may complicate and exacerbate headache [26]. Also, it was suggested that smartphone overuse might lead to depression and/or anxiety which may be related to headache [21]. Having to concentrate on the images that were closest to the screen can cause headache [27]. Screen movement, flicker and certain patterns have been reported to be migraine triggers. Bright light and glare can also trigger headache or make symptoms worse [28].

Several limitations of the present study should be considered. The relatively smaller study population due to the rarity of smartphone non-user students was one of the limitations of this study. All the participants were university students and they may not be generalized to the public population. All subjects were well-educated adult. Longitudinal studies and multi-samples of different educational and age backgrounds are needed. Cross-sectional design, which is not the best way to evaluate any causal relations, also limited the results. Furthermore, we did not assess other headache triggers such as anxiety, depression, and sleep disturbance. Moreover, the literature in this field is not yet rich enough.

In conclusion, this study shows that smartphone overusers may experience headaches. Smartphones play a large part in the daily life of university students. Headache can affect performance and productivity of smartphone users in a big way. So, the impact of smartphone use on health should be attentively monitored among the university students to prevent the detrimental effects of smartphone use. Our study may also shed light on future studies with longer follow up periods to investigate the behavioral interventions in the individuals with frequent headaches in association with smartphone use.

\section{References}

1. Demirci K, Orhan H, Demirdas A, Akpınar A, Sert H (2014) Validity and reliability of the Turkish version of the Smartphone Addiction Scale in a younger population. Bulletin Clin Psychopharmacol 24: 226-234.

2. Sim MS, Kim EM (2011) The smart phone use survey 2011. Korea communications commission press, Seoul, pp. 21-23.

3. Hwang KH, Yoo YS, Cho OH (2012) Smartphone overuse and upper extremity pain, anxiety, depression, and interpersonal relationships among college Students. Korea Constents Association12: 365-375.

4. Kwon M, Kim DJ, Cho H, Yang S (2013) The smartphone addiction scale: development and validation of a short version for adolescents. PloS One 8: e83558.

5. Lee H, Ahn H, Choi S, Choi W (2014) The SAMS: Smartphone Addiction Management System and verification. J Med Syst 38: 1.

6. South Korea National Information Society Agency (2011) Internet Addiction Survey 2011. National Information Society Agency, Seoul, pp. 118-119.

7. Kwon M, Lee JY, Won WY, Park JW, Min JA, et al. (2013) Development and validation of a smartphone addiction scale (SAS). PloS One 8: e56936.

8. Kuss DJ, Griffiths MD (2011) Online social networking and addiction--a review of the psychological literature. Int J Environ Res Public Health 8: 3528-3552.

9. Kang JH, Park RY, Lee SJ, Kim JY, Yoon SR, et al. (2012) The effect of the forward head posture on postural balance in long time computer based worker. Ann Rehabil Med 36: 98-104.

10. Kim YG, Kang MY, Kim WJ, Jang HY, Oh JS (2013) Influence of the duration of smartphone usage on flexion angles of the cervical and lumbar spine and on reposition error in the cervical spine. Physical Therapy Korea 20: 10-17.

11. Headache Classification Subcommittee of the International Headache Society (2004) The international classification of headache disorders: 2nd edition. Cephalalgia 24 Suppl 1: 9-160

12. Kayode AE, Idowu BN, Gbenga OS (2014) Prediction of an increase in eye problems, in ljebu-ode and ljebu north local government area of Ogun state in the nearest future as a result of spending much time on computer/ smartphone. Int J Cur Res Rev 6: 35-40.

13. Lee JI, Song HS (2014) The correlation analysis between hours of smartphone use and neck pain in the Gachon University students. The Acupuncture 31: 99-109.

14. Lemola S, Perkinson-Gloor N, Brand S, Dewald-Kaufmann JF, Grob A (2015) Adolescents' electronic media use at night, sleep disturbance, and depressive symptoms in the smartphone age. J Youth Adolesc 44: 405-418. 
15. Lee J, Seo K (2014) The comparison of cervical repositioning errors according to the smartphone addiction grades. J Phys Ther Sci 26: 595-598.

16. Khan MM (2008) Adverse effects of excessive mobile phone use. Int J Occup Med Environ Health 21: 289-293.

17. Szyjkowska A, Gadzicka E, Szymczak W, Bortkiewicz A (2014) The risk of subjective symptoms in mobile phone users in Poland--an epidemiological study. Int J Occup Med Environ Health 27: 293-303.

18. Chu MK, Song HG, Kim C, Lee BC (2011) Clinical features of headache associated with mobile phone use: a cross-sectional study in university students. BMC Neurol 11: 115.

19. Huber R, Treyer V, Borbely AA, Schuderer J, Gottselig JM, et al. (2002) Electromagnetic fields, such as those from mobile phones, alter regional cerebral blood flow and sleep and waking EEG. J Sleep Res 11: 289-295.

20. Inal EE, Demirci K, Çetintürk A, Akgönül M, Savaş S (2015) Effects of smartphone overuse on hand function, pinch strength, and the median nerve. Muscle Nerve 52: 183-188.

21. Demirci K, Akgönül M, Akpinar A (2015) Relationship of smartphone use severity with sleep quality, depression, and anxiety in university students. J Behav Addict 4: 85-92.
22. Redmayne M, Smith E, Abramson MJ (2013) The relationship between adolescents' well-being and their wireless phone use: a cross sectional study. Environ Health 12: 90.

23. Frey $\mathrm{AH}$ (1998) Headaches from cellular telephones: are they real and what are the implications? Environ Health Perspect 106: 101-113.

24. Fernández-de-las-Peñas C, Alonso-Blanco C, Cuadrado ML, Pareja JA (2006) Forward head posture and neck mobility in chronic tension-type headache: a blinded, controlled study. Cephalalgia 26: 314-319.

25. Kidd RF, Nelson R (1993) Musculoskeletal dysfunction of the neck in migraine and tension headache. Headache 33: 566-569.

26. Rains JC, Davis RE, Smitherman TA (2015) Tension-type headache and sleep. Curr Neurol Neurosci Rep 15: 520.

27. Shantakumari N, Eldeeb R, Sreedharan J, Gopal K (2014) Computer use and vision-related problems among university students in ajman, United arab emirate. Ann Med Health Sci Res 4: 258-263.

28. Kowacs PA, Piovesan EJ, Werneck LC, Fameli H, Pereira da Silva H (2004) Headache related to a specific screen flickering frequency band. Cephalalgia 24: 408-410. 